\title{
What did we learn from a pilot trial to inform the scale-up of a training based on the Mental Health Gap Action Programme in Tunisia?
}

Jessica Spagnolo, ${ }^{1,2}$ Fatma Charfi, ${ }^{3,45}$ Nesrine Bram, ${ }^{4,6}$ Leila Larbi Doghri ${ }^{7}$ and Wahid Melki ${ }^{4,8,9}$

${ }^{1}$ Centre de recherche Charles-Le-Moyne-Saguenay-Lac-St-Jean sur les innovations en santé Campus de Longueuil - Université de Sherbrooke, Québec, Canada. ${ }^{2}$ Département des sciences de la santé communautaire, Faculté de médecine et des sciences de la santé, Université de Sherbrooke, Québec, Canada. ${ }^{3}$ Department of Child Psychiatry, Mongi-Slim Hospital, Tunis, Tunisia. ${ }^{4}$ Faculty of Medicine of Tunis, University of Tunis El Manar, Tunis, Tunisia. ${ }^{5}$ Suicide Prevention Technical Committee, Ministry of Health, Tunis, Tunisia (Correspondence to: F. Charfi: fatmacharfiı@gmail.com). ${ }^{6}$ Department of Pyschiatry C, Razi Hospital, Mabouba, Tunisia. ${ }^{7}$ Essaha Aziza Programme, Ministry of Health, Tunis, Tunisia. ${ }^{8}$ Committee for Mental Health Promotion, Ministry of Health, Tunis, Tunisia. ${ }^{9}$ Department of Psychiatry D, Razi Hospital, Mabouba, Tunisia.

Citation: Spagnolo J; Charfi F; Bram N; Doghri LL; Melki W. What did we learn from a pilot trial to inform the scale-up of training based on the Mental Health Gap Action Programme in Tunisia? East Mediterr Health J. 2021;27(6):542-545. https://doi.org/10.26719/emhj.21.021

Received: 21/06/20; accepted:12/08/20

Copyright ( $)$ World Health Organization (WHO) 2021. Open Access. Some rights reserved. This work is available under the CC BY-NC-SA 3.0 IGO license (https://creativecommons.org/licenses/by-nc-sa/3.o/igo)

\section{Background}

Primary care is an important part of global mental health, including in the Eastern Mediterranean Region (EMR). It is a promising way of increasing access to needed, timely, comprehensive and effective mental health services (1). Given the connection between mental and physical illness (2), vertical (stand-alone) programmes targeting mental illness and substance use disorders, traditionally favoured in low- and middle-income countries (LMICs), are not as effective as integrated approaches (3). The EMR has developed a regional framework that identifies feasible and cost-effective solutions to better mental health care, including the further integration of mental health into primary care settings (4) through, for example, the involvement of primary care physicians (PCPs) in mental health care (5). While this solution is promising, with many countries in the EMR that have models of care that rely on primary care staff $(6,7)$, persistent gaps have been identified in their mental health capacity $(8-10)$. The World Health Organization (WHO) has thus recognized mental health care as a core component of PCPs' training (11).

The Mental Health Gap Action Programme (mhGAP) Intervention Guide (IG) was developed by WHO in 2010 to increase mental health capacity in primary care and community-based settings by training nonspecialists, such as PCPs, thus improving service access for a wider population (12). mhGAP-based training has been implemented in several countries in the EMR, including Afghanistan (13,14), Egypt (13), Iraq (15), Lebanon (13, 16), Libya (13), Pakistan (13,17,18), Qatar (13), Sudan (19), Syrian Arab Republic (13,15), and Tunisia (20). The training has been used in the Region to enhance the mental health capacity of for example physicians, social workers, nurses, community health workers, family volunteers, psychosocial staff of humanitarian agencies, and pregnant women $(13-20)$.

The first mhGAP-training programme in Tunisia (using version 1.0) (12) was offered to PCPs in the
Greater Tunis area between February and May 2016. Its implementation and evaluation were undertaken collaboratively by members of the Tunisian Ministry of Health, the School of Public Health at Universite de Montréal (Canada), and the WHO Office in Tunisia. Training of local trainers (3 psychiatrists) and tutors (7 PCPs in charge of continuing medical education in their respective health sectors and supporting trainees during and after the programme) was held at the end of 2015 and offered by a nonlocal consultant. The mhGAPbased training programme was meant to address PCPs' capacity gaps in depression, suicide/self-harm, psychosis, and problems related to substance use (10), and modules were selected as priority conditions by members of the Ministry of Health involved in the implementation of the mhGAP-based training programme.

The lessons that we have learned to inform the scale-up of a mental health training programme may be useful to other countries of the EMR interested in implementing and/or scaling-up task-sharing initiatives to support commitment to integrating mental health into primary care settings $(6,7)$. The training scale-up is being offered under the programme Essaha Aziza (or "health is precious" in Arabic), which is funded by the European Union to promote proximity health services by ensuring availability of infrastructure and training for personnel in 13 of the 24 Tunisian governorates. The remaining 11 governorates will be offered mental health training through funding provided by WHO.

\section{Modifying policy}

We found through interviews with PCPs after their participation in the pilot training programme that legislation drafted in the 1990s prevented them from prescribing certain psychotropic medications available in Tunisia and listed in the mhGAP-IG (21). This legislation was still in place during the pilot phase (21). For scale-up of the training programme, it was important to revise the legislation. Without revision, PCPs may be encouraged to 
refer people to specialized mental health services despite their training in administering pharmacological treatment listed in the mhGAP-IG and available in Tunisia. The Ministry of Health is committed to finding a solution to address this prescription obstacle for the scale-up phase.

\section{Informing training content}

The mhGAP-IG modules of depression, psychosis and problems related to substance use (12) were included in the training programme for scale-up. Of note, version 1.0 of the mhGAP-IG was used, given that we had already adapted the training material to the local primary healthcare context during the pilot phase (20). Three changes were made in the choice of the remaining modules, in response to evidence from interviews conducted with some trained PCPs to better understand their perceptions of the pilot programme (21). First, in the 2016 implementation of the mhGAP-based training, PCPs vocalized wanting additional training, including in the suicide/ self-harm module to treat and manage suicidal behaviour. This was important given the uneven distribution of mental health specialists across the country amid a recorded increase in suicide and suicidal behaviour (22). The training programme for scale-up was complemented by a suicidal behaviour and risk management course already piloted in Tunisia. Second, Tunisian experts are elaborating a national strategy for the early detection of autism spectrum disorders by PCPs. To support PCPs in early detection, a module on autism spectrum disorders developed by Tunisian experts was included in the training programme for scale-up. This module was perceived a better fit to the country's needs than the mhGAP-IG module on Child and Adolescent Mental and Behavioural Disorders (12). Third, the accompanying training material for the mhGAP module on conditions specifically related to stress (23) was not available in the working languages of Tunisia during the first mhGAP-based implementation (21). This was problematic since problems related to trauma and stress are more pronounced in the country. Scale-up of the training programme includes the available mhGAP module and accompanying training material on conditions specifically related to stress (23). Of note, in the context of COVID-19, many modules offered in the programme scale-up are timely in addressing the negative mental health consequences of the COVID-19 pandemic, including over the longer term (i.e., post-traumatic stress, depressive and anxiety symptoms) (24).

\section{Operationalizing the mental health strategy}

Tunisia is one of the few countries to have produced a mental health strategy in the EMR, which is one of the WHO Regions with the least number of countries to have produced a mental health plan (25). One of the main objectives of the 2013 National Strategy for Mental Health Promotion (26) is to promote the integration of mental health within primary care settings, notably through the training of PCPs. The pilot implementation of the mhGAP-IG was an attempt to further operationalize one of the Strategy's main objectives and to generate evidence on PCP mental health training. The pilot mhGAP-based training had a significant short-term impact (6 weeks post-training) on mental health knowledge, attitudes, and self-efficacy scores, but not on self-reported practice. When comparing results before and 18 months after training, these changes were maintained, and self-reported referral scores decreased (20). The generated evidence from the pilot evaluation was used to promote the inclusion of the mental health training under the umbrella of initiatives offered by Essaha Aziza. Specifically, this programme aims to enhance primary care system capacity to ensure that health services are more readily available, including for the most at-risk. The inclusion of PCPs' mental health training under the programme's mandate is a testament to the growing importance placed on mental health prevention, promotion and treatment in public health policy and practice in Tunisia.

\section{Encouraging sustainability}

The first implementation of the mhGAP-based training relied on 3 trainer-psychiatrists and a network of PCPs with advanced mental health knowledge to support trainees during and after training (20). They were trained by a nonlocal consultant. For the scale-up of the training programme, a cascade model was used. A cascade model refers to "a series of training processes, each occurring as the result of the one before" (27) and is used to help diffuse expertise in the mental health sector (17,28-31). Specifically, a former local trainer for the first implementation of the mhGAP-based programme trained psychiatrists from the 4 Faculties of Medicine in Tunisia (Tunis, Sfax, Monastir and Sousse) in the mhGAP modules. They, in turn, will train 20 PCPs from each governorate in Tunisia as mental health resources (or mental health focal points) in frontline care, after which they will be available to provide support to other PCPs in the area. Fifty-eight PCPs with the role of mental health resource were trained between January and March 2020 - bearing in mind the interruption to the training caused by the COVID-19 restrictions. Supervision by telemedicine will be offered in 1 governorate of Tunisia as a pilot to assess a more structured way of providing support post-training.

This cascade model of training was developed not only to encourage sustainability of the training's effects through local capacity building, but also to further support collaborations between primary and specialized mental health services. Specifically, in Tunisia, some governorates do not have psychiatrists, as they are overrepresented in large cities along the coastline and in the private sector (32). Sectorization allows for public mental health services to be organized according to geographical sectors (i.e., governorates), with each sector affiliated with a university inpatient department of psychiatry $(32,33)$. The university psychiatric inpatient units are responsible for organizing training and supervision sessions for primary healthcare professionals and for 
coordinating referrals (32). This sectorization structure will be respected and encouraged through the scaled-up training and beyond. Psychiatrists from the 4 Faculties of Medicine trained to use the mhGAP-IG will teach and support PCPs working in the governorates with which they are affiliated, to ensure that mental health knowledge and skills are maintained.

This new training programme for scale-up across the country aims to: (1) build on evidence from the first implementation of the mhGAP-based training $(20,21)$ to improve mental health policy and to operationalize the National Mental Health Promotion Strategy; and (2) mobilize and include more local knowledge, initiatives and experts in supporting PCPs' mental health capacity. As Mills and Lacroix (2019) mentioned, these unique ways of working in local contexts with standardized documents like the mhGAP "evidences creative adaptations of the guidelines linked to people's own philosophies, and societal understandings of mental health" (35). With these considerations of context, culture and evidence from pilot-testing, task-sharing initiatives through training and specialist support, as well as their positive effects may be accepted and sustained.

\section{References}

1. Funk M, Saraceno B, Drew N, Faydi E. Integrating mental health into primary healthcare. Ment Health Fam Med. 2008 Mar;5(1):5-8. PMID:22477840

2. Kessler RC, Alonso J, Chatterjee S, He Y. The epidemiology and impact of mental disorders. In: Patel V et al., editors. Global mental health: principles and practice. New York: Oxford University Press; 2014.

3. Thornicroft G, Ahuja S, Barber S, Chishol D, Collins PY, Docrat S, et al. Integrated care for people with long-term mental and physical health conditions in low-income and middle-income countries. Lancet Psychiatry. 2019 Feb;6(2):174-86. https://doi. org/10.1016/S2215-0366(18)30298-o PMID:30449711

4. Gater R, Saeed K. Scaling up action for mental health in the Eastern Mediterranean Region: an overview. East Mediterr Health J. 2015 Sep 28;21(7):535-45. https://doi.org/10.26719/2015.21.7.535 PMID:26442897

5. Rahman A. Mental disorders in the Eastern Mediterranean Region. Int J Public Health. 2018;63, 9-10. https://doi.org/10.1007/ s00038-017-0986-1

6. van Weel C, Alnasir F, Farahat T, Usta J, Osman M, Abdulmalik M, et al. Primary healthcare policy implementation in the Eastern Mediterranean region: experiences of six countries. Eur J Gen Pract. 2018 Dec;24(1):39-44. https://doi.org/10.1080/13814788.2 017.1397624 PMID:29168411

7. Nashat N, Hadjij R, Al Dabbagh AM, Tarawneh MR, Alduwaisan H, Zohra F, et al. Primary care healthcare policy implementation in the Eastern Mediterranean region; experiences of six countries: part II. Eur J Gen Pract. 2020 Dec;26(1):1-6. https://doi.org/10.1 080/13814788.2019.1640210 PMID:31368386

8. Al Saif F, Al Shakhoori H, Nooh S, Jahrami H. Association between attitudes of stigma toward mental illness and attitudes toward adoption of evidence-based practice within health care providers in Bahrain. PLoS One. 2019 Dec 2;14(12):e0025738. https://doi. org/10.1371/journal.pone.0225738 PMID:31790468

9. Haddad M, Waqas A, Qayyum W, Shams M, Malik S. The attitudes and beliefs of Pakistani medical practitioners about depression: a cross-sectional study in Lahore using the revised depression attitude questionnaires (R-DAQ). BMC Psychiatry. 2016 Oct 18;16(1):349. https://doi.org/10.1186/s12888-016-1069-1 PMID:27756274

10. Spagnolo J, Champagne F, Leduc N, Rivard M, Piat M, Laporta M, et al. Mental health knowledge, attitudes, and self-efficacy among primary care physicians working in the Greater Tunis area of Tunisia. Int J Mental Health Syst. 2018 Oct 26;12:63. https:// doi.org/10.1186/s13033-018-0243-x PMID:30386422

11. Integrating mental health into primary care: a global perspective. Geneva: World Health Organization and World Organization of Family Doctors; 2008 (http://www.who.int/mental_health/resources/mentalhealth_PHC_2008.pdf, accessed 12 February 2020).

12. mhGAP intervention guide for mental, neurological and substance use disorders in non-specialized health settings (version 1.0). Geneva: World Health Organization; 2010 (http://apps.who.int/iris/bitstream/10665/44406/1/9789241548069_eng.pdf, accessed 10 June 2020).

13. Gavlak D. Learning to heal minds in the Eastern Mediterranean. Bull World Health Organ. 2016 Oct 1;94:714-5. https://doi. org/10.2471/BLT.16.021016 PMID:27843159

14. Khoja S, Scott R, Husyin N, Durrani H, Arif M, Faqiri F, et al. Impact of simple conventional and telehealth solutions on improving mental health in Afghanistan. J Telemed Telecare. 2016 Dec;22(8):295-8. https://doi.org/10.1177/1357633X16674631 PMID:27799454

15. Hughes P, Hijazi Z, Saeed K. Improving access to mental healthcare for displaced Syrians: case studies from Syria, Iraq and Turkey. BJPsych Int. 2016 Nov 1;13(4):84-8. https://doi.org/10.1192/s2056474000001392 PMID:29093914

16. Chammay RE, Karam E, Ammar W. Mental health reform in Lebanon and the Syrian crisis. Lancet Psychiatry. 2016 Mar;3(3):202-3. https://doi.org/10.1016/S2215-0366(16)00055-9 PMID:26946388 
17. Hamdani SU, Minhas FA, Iqbal Z, Rahman A. Model for service delivery for developmental disorders in low-income countries. Pediatrics. 2015 Dec;136(6):1166-72. https://doi.org/10.1542/peds.2015-0861 PMID:26598452

18. Humayun A, Haq I, Khan FR, Azad N, Khan MM, Weissbecker I. Implementing mhGAP training to strengthen existing services for an internally displaced population in Pakistan. Glob Ment Health. 2017 Apr 3;4:e6. https://doi.org/10.1017/gmh.2017.1 PMID:28596907

19. Sherese A, Saeed K, Hughes P. Evaluation of a mental health training project in the Republic of the Sudan using the mental health gap action programme curriculum. Int Psychiatry. 2012 May 1;9(2):43-5. PMID:31508118

20. Spagnolo J, Champagne F, Leduc N, Rivard M, Melki W, Piat M, et al. Building capacity in mental health care in low- and middle-income countries by training primary care physicians using the mhGAP: a randomized controlled trial. Health Policy Plan. 2020 Mar 1;35(2):186-98. https://doi.org/10.1093/heapol/czz138 PMID:31794027

21. Spagnolo J, Champagne F, Leduc N, Melki W, Piat M, Laporta M, et al. "We find what we look for, and we look for what we know": Factors interacting with a mental health training program to influence its expected outcomes in Tunisia. BMC Public Health. 2018 Dec 20;18(1):1398. https://doi.org/10.1186/s12889-018-6261-4 PMID:30572941

22. Ben Khelil M, Gharbaoui M, Farhani F, Zaafrane M, Harzallah H, Allouche M, et al. Impact of the Tunisian Revolution on homicide and suicide rates in Tunisia. Int J Public Health. 2016 Dec;61(9):995-1002. https://doi.org/10.1007/s00038-016-0834-8 PMID:27193575

23. Assessment and management of conditions specifically related to stress: mhGAP Intervention Guide Module. Geneva: World Health Organization; 2013 (http://apps.who.int/iris/bitstream/10665/85623/1/9789241505932_eng.pdf, accessed 22 March 2021).

24. Policy brief: COVID-19 and the need for action on mental health. United Nations; 2020 (https://unsdg.un.org/sites/default/ files/2020-05/UN-Policy-Brief-COVID-19-and-mental-health.pdf, accessed 22 March 2021).

25. Mental Health Atlas 2017. Geneva: World Health Organization; 2018 (http://apps.who.int/iris/bitstream/hand le/10665/272735/9789241514019-eng.pdf?ua=1, accessed 22 March 2021).

26. The National Strategy for the Promotion of Mental Health. Tunisia: Ministry of Health; 2013 (https://www.mindbank.info/ item/6277, accessed 21 July 2020).

27. Cheese J. Cascading the training. Programmed Learn Educ Technol. 1986;23:248-52. https://doi.org/10.1080/0033039860230309

28. Gask L, Coupe N, Green G. An evaluation of the implementation of cascade training for suicide prevention during the 'Choose Life' initiative in Scotland - utilizing normalization process theory. BMC Health Serv Res. 2019 Aug 20;19(1):588. https://doi. org/10.1186/s12913-019-4398-1 PMID:31429739

29. Gureje O, Abdulmalik J, Kola L, Musa E, Yasamy MT, Adebayo K. Integrating mental health into primary care in Nigeria: report of a demonstration project using the mental health gap action programme intervention guide. BMC Health Serv Res. 2015 Jun 21;15:242. https://doi.org/10.1186/s12913-015-0911-3 PMID:26094025

30. Kutcher S, Wei Y, Gilberds H, Brown A, Ubuguyu O, Njau T, et al. Addressing adolescent depression in Tanzania: positive primary care workforce outcomes using a training cascade model. Depress Res Treat. 2017;2017:9109086. https://doi. org/10.1155/2017/9109086 PMID:29333294

31. Zafar S, Sikander S, Hamdani SU, Atif N, Akhtar P, Nazir H, et al. The effectiveness of technology-assisted cascade training and supervision of community health workers in delivering the Thinking Healthy Program for perinatal depression in a post-conflict area of Pakistan - study protocol for a randomized controlled trial. Trials. 2016 Apr 6;17:188. https://doi.org/10.1186/s13063016-1308-2 PMID:27048477

32. Charfi F, Ouali U, Spagnolo J, Belhadj A, Nacef F, Saidi O, et al. Highlighting successes and challenges of the mental health system in Tunisia: an overview of services, facilities, and human resources. J Ment Health. 2021 Feb 14;1-9. https://doi.org/10.1080/0 9638237.2021.1875414 PMID:33583305

33. Ben Neticha K, Aissa A, Abbes M, Ben Ammar H, Khelifa E, El Hechmi Z. La résistance à la sectorisation: exemple du gouvernorat de Nabeul en Tunisie. East Mediterr Health J. 2017 Jun 14;23(4):314-20. https://doi.org/10.26719/2017.23.4.314 PMID:28634983

34. Mills C, Lacroix K. Reflections on doing training for the World Health Organization's mental health gap action program intervention guide (mhGAP-IG). Int J Ment Health. 2019;48(4):309-22. https://doi.org/10.1080/00207411.2019.1683681 